\title{
Causes of endemic radiation in the Caribbean: evidence from the historical biogeography and diversification of the butterfly genus Calisto (Nymphalidae: Satyrinae: Satyrini)
}

\author{
Pável Matos-Maravi ${ }^{1}{ }^{2 *}$, Rayner Núñez Águila ${ }^{3}$, Carlos Peña ${ }^{1}$, Jacqueline Y Miller ${ }^{4}$, Andrei Sourakov $^{4}$
} and Niklas Wahlberg'

\begin{abstract}
Background: Calisto is the largest butterfly genus in the West Indies but its systematics, historical biogeography and the causes of its diversification have not been previously rigorously evaluated. Several studies attempting to explain the wide-ranging diversity of Calisto gave different weights to vicariance, dispersal and adaptive radiation. We utilized molecular phylogenetic approaches and secondary calibrations points to estimate lineage ages. In addition, we used the dispersal-extinction-cladogenesis model and Caribbean paleogeographical information to reconstruct ancestral geographical distributions. We also evaluated different models of diversification to estimate the dynamics of lineage radiation within Calisto. By understanding the evolution of Calisto butterflies, we attempt to identify the main processes acting on insular insect diversity and the causes of its origin and its maintenance.

Results: The crown age of Calisto was estimated to the early Oligocene ( $31 \pm 5 \mathrm{Ma}$ ), and a single shift in diversification rate following a diversity-dependent speciation process was the best explanation for the present-day diversity found within the genus. A major increase in diversification rate was recovered at $14 \mathrm{Ma}$, following geological arrangements that favoured the availability of empty niches. Inferred ancestral distributional ranges suggested that the origin of extant Calisto is in agreement with a vicariant model and the origin of the Cuban lineage was likely the result of vicariance caused by the Cuba-Hispaniola split. A long-distance dispersal was the best explanation for the colonization of Jamaica and the Bahamas.

Conclusions: The ancestral geographical distribution of Calisto is in line with the paleogeographical model of Caribbean colonization, which favours island-to-island vicariance. Because the sister lineage of Calisto remains ambiguous, its arrival to the West Indies remains to be explained, although, given its age and historical biogeography, the hypothesized GAARlandia land bridge might have been a plausible introduction route from continental America. Intra-island radiation caused by ecological innovation and the abiotic creation of niche spaces was found to be the main force shaping Calisto diversity and island endemism in Hispaniola and Cuba.
\end{abstract}

Keywords: Caribbean, Ecological limits, Historical biogeography, Intra-island diversification, Island-island vicariance, Lepidoptera, Molecular phylogeny

\footnotetext{
* Correspondence: pavelm14@gmail.com

'Laboratory of Genetics, Department of Biology, University of Turku, Fl-20014 Turku, Finland

${ }^{2}$ School of Biological Sciences, University of South Bohemia and Institute of Entomology, Biology Centre AS CR, CZ-37005 Ceske Budejovice, Czech Republic

Full list of author information is available at the end of the article
} 


\section{Background}

The Caribbean has been an important model system for studying biotic over-water dispersal from continents and island colonization [1-4], as well as vicariance [5,6] as mechanisms for the origin of diversity, and within-island diversification as mediators of species richness and endemism $[7,8]$. The geological evolution of the region has certainly had a strong influence on the diversification of species there, and a general understanding of the former is crucial to an understanding of the latter.

The larger islands of the Greater Antilles (i.e. Cuba, Hispaniola, Jamaica and Puerto Rico) were repeatedly submerged until the mid/late Eocene ( 40 Ma) [3,6]. A general terrene uplift is likely to have occurred during the mid-Eocene and the early Oligocene ( 45-30 Ma), and some authors hypothesized the existence of a land corridor connecting northern South America to the Greater Antilles and subaerial Aves Ridge (GAARlandia, $\sim 35-33 \mathrm{Ma}$ ) [6,9], although this is still under debate [10]. Hispaniola and Puerto Rico were physically connected until the formation of the Mona Passage, becoming fully separated during the late Oligocene to early Miocene ( 30-20 Ma) [11,12]. Later, during the early to midMiocene, the aerial connection between eastern Cuba and northern Hispaniola was interrupted by the expansion of the Windward Passage ( 17-14 Ma) [6,13].

Northern and southern Hispaniola paleoislands collided in the mid Miocene (ca. 15-10 Ma) $[6,14,15]$, triggering the initial uplift of south-western Hispaniolan mountains as well as the significant elevation of the Cordillera Central $[16,17]$. Multiple marine incursions in the Cul-de-Sac/ Enriquillo depression repeatedly separated northern and southern paleoislands until the Plio-Pleistocene ( 2.5 Ma) $[15,18]$. Cuba was fragmented into distinct land blocks comprising the current western, central and eastern parts of the island until the late Miocene, when the closure of the Havana-Matanzas Channel began some 8-6 Ma [6]. On the other side, Jamaica was continuously submerged until ca. $12 \mathrm{Ma}$ [19]. The western Jamaica land block was temporally aerial and connected to Central America during the early to mid-Eocene $[6,20]$, whereas eastern Jamaica (Blue Mountains Block) was apparently connected to GAARlandia through the southern peninsula of Hispaniola during $255-33 \mathrm{Ma}[4,6]$. Most Bahamian shallows and keys were repeatedly submerged during the Pliocene and Pleistocene ( 4-0.5 Ma) [21].

The butterfly genus Calisto (Nymphalidae, Satyrinae, Satyrini) is the only satyrine group occurring in the Caribbean region [22,23]. This genus exhibits remarkable radiation and significantly contributes to the high butterfly endemism seen in the region [24,25]. The genus Calisto comprises 44 described species, all geographically restricted to single islands [23,26-29]; 11 distributed in Cuba, 1 in Puerto Rico, 1 in Anegada Island, 1 in Jamaica, 2 in the
Bahamas and the remaining 28 species occurring in Hispaniola. Molecular data has given insight into the cryptic condition of several taxa in Hispaniola [27], as well as assisted in determining the phylogenetic relationships of Cuban taxa [28].

Even though the monophyly of the genus appears to be clear [27], its position within the taxonomic tribe Satyrini has not been resolved. Morphological studies classify Calisto within the subtribe Pronophilina [23], closely related to the Neotropical genus Eretris [30,31]. However, this has not been corroborated at the molecular level [32]. Certain morphological similarities have even led some authors to propose African affinities with, for instance, the subtribe Ypthimina (Satyrini) [33] and the satyrine tribe Dirini [34,35].

Regardless of the phylogenetic position of Calisto, a continental origin of the genus is the most plausible explanation, as no other extant satyrine butterflies with the potential of being a closely related group are found in the Greater Antilles; thus, its ancestors would have necessarily arrived to the Caribbean from the nearby American continent $[31,33,36]$. Once Calisto colonized the Greater Antilles, further differentiation by vicariance [31,37], within-island diversification [28,36] or adaptive radiation [27] might have shaped the evolution of these butterflies.

In this study, we aim to elucidate the phylogenetic affinities and to identify the main drivers of the diversification and distribution of Calisto by using a secondarily calibrated molecular phylogeny. We also aim to reconstruct the historical biogeography of Calisto and to evaluate possible changes in diversification rates throughout the evolution of the genus. Intra-island differentiation appears to be an important factor for the radiation of these butterflies, a phenomenon observed in other Caribbean animal lineages [2,4,9,38-40]. However, even though rapid diversification driven by ecological evolution is plausible explanation considering the diversity of Caribbean habitats, niche saturation and island size may have imposed diversification limits [38] which could have restricted the diversity and geographical distribution of Calisto.

\section{Results}

\section{Systematics and divergence dates of Calisto}

Our phylogenetic inferences using single gene datasets are congruent with the combined analyses, recovering the main clades within Calisto (Additional file 1). Moreover, the combined analyses were consistent regardless of the method used and the partitioning strategy (Figure 1). A summary of the dataset properties is presented in Table 1.

Calisto nubila split early in the evolution of the genus, becoming an old and separate entity. The lineage did not apparently diversify further within Puerto Rico, although $C$. anegadensis on Anegada Island might have been derived from it based on morphological similarities 


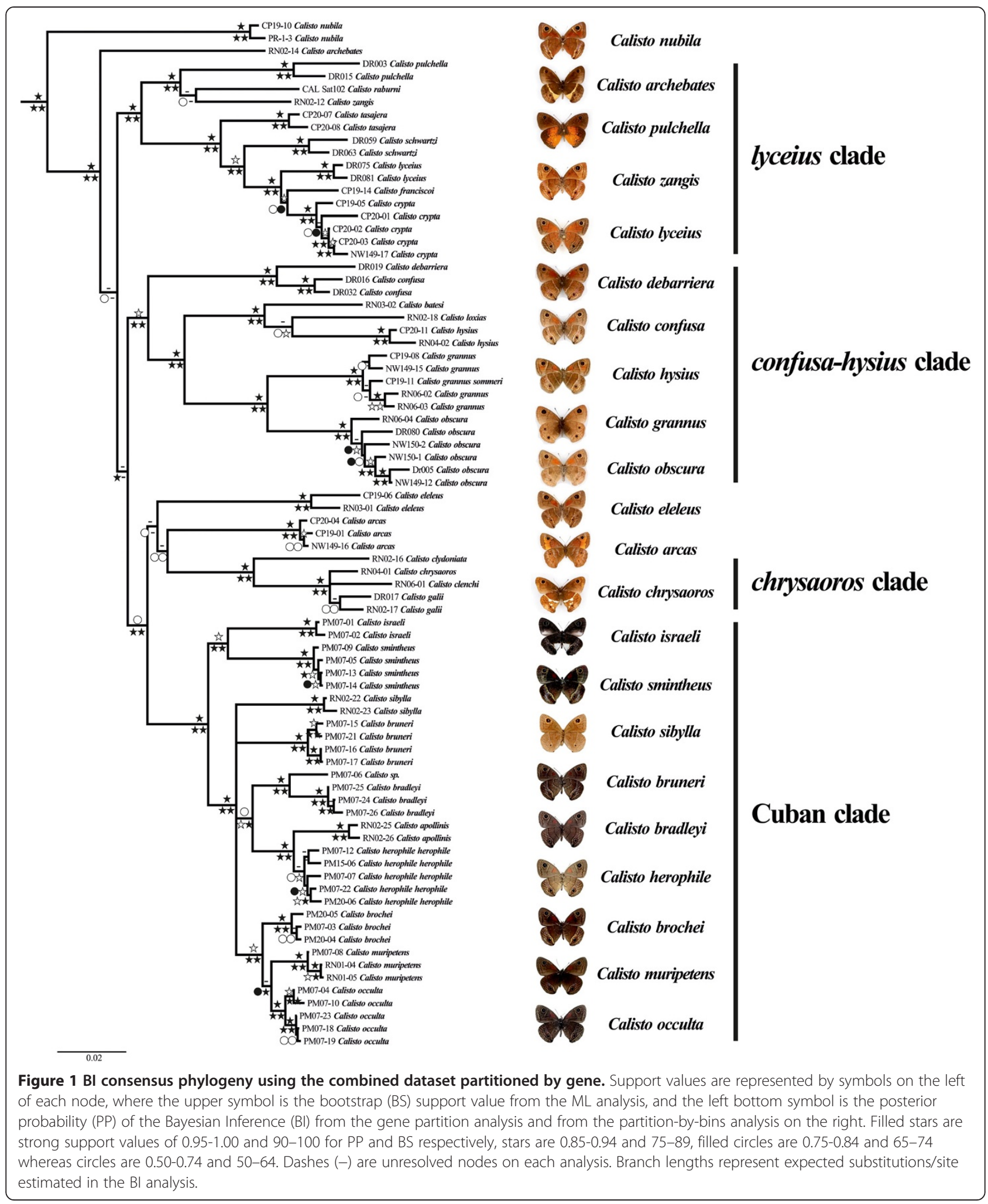

[26]. Three main monophyletic groups from Hispaniola are identified: the lyceius-, the confusa-hysius and the chrysaoros clades. Calisto zangis from Jamaica is likely to have had Hispaniolan ancestors as it belongs to the "lyceius clade". The monophyletic group consisting of Cuban and Bahamian Calisto is closely related to Hispaniolan lineages such as $C$. arcas and the "chrysaoros clade", although the relationship among them was not 
Table 1 Partition strategies for phylogenetic analyses of the combined dataset

\begin{tabular}{|c|c|c|c|c|c|c|c|}
\hline Partitions & Base pairs & Variable & Informative & Subs. model & $m$ (ratemult) & Alpha ( $\Gamma$ shape) & Tree likelihood \\
\hline \multicolumn{8}{|c|}{ Gene strategy } \\
\hline $\mathrm{COI}$ & 1487 & 651 & 486 & $\mathrm{GTR}+\mathrm{G}$ & 1.569 & 0.245 & -18584.5 \\
\hline CAD & 850 & 319 & 218 & $H K Y+G$ & 0.749 & 0.282 & -4766.8 \\
\hline EF1a & 1240 & 432 & 290 & $\mathrm{GTR}+\mathrm{G}$ & 0.768 & 0.222 & -21045.8 \\
\hline GAPDH & 691 & 264 & 196 & $\mathrm{GTR}+\mathrm{G}$ & 0.864 & 0.232 & -13990.5 \\
\hline RPS5 & 617 & 228 & 183 & $\mathrm{GTR}+\mathrm{G}$ & 0.694 & 0.198 & -11920.2 \\
\hline WINGLESS & 400 & 191 & 130 & $K 80+G$ & 0.848 & 0.34 & -8617.8 \\
\hline \multicolumn{8}{|c|}{ "Bin" strategy } \\
\hline BIN1 & 2727 & - & - & F81 & 0.0002 & - & - \\
\hline BIN2-BIN10 & 652 & - & - & GTR & 0.57 & - & - \\
\hline BIN11 & 1269 & - & - & $G T R+G$ & 1.457 & 1.601 & - \\
\hline BIN12 & 637 & - & - & $\mathrm{GTR}+\mathrm{G}$ & 4.828 & 4.389 & - \\
\hline
\end{tabular}

Number of variable and phylogenetically informative sites in our Calisto data are shown by gene partition. Substitution model was selected based on BIC calculations in jModelTest [41]. Rate multiplier $(m)$ and Gamma-shape (alpha) parameters are from BI whereas the tree likelihood for each gene partition are from the dating analysis using normal distribution for the calibration points and the birth-death process. Other dating analyses have similar values as shown in tree likelihood.

resolved with strong support (Figures 1 and 2). A revised checklist of the genus Calisto is presented in Table 2.

The genus Calisto was not recovered within any valid Satyrini subtribes. Instead, our BEAST reconstructions place it sister to all sampled subtribes except Euptychiina with low support values (posterior probability around 0.60-0.65) (Additional file 1). The exclusion of the genus Euptychia (which apparently caused long branch attraction in a different dataset [32]) only increases the support for such a placement to moderate values (around 0.800.85 ). Using birth-death/Yule and normal/uniform as tree processes and calibration distributions respectively does not result in any significant difference in both tree topology and estimated ages (Additional file 1, Figure 2). Height posterior distributions displayed normally whereas summarizing the trees as means or medians height showed no significant difference. The crown age of Calisto is inferred at $31 \mathrm{Ma}( \pm 5 \mathrm{Ma})$ in all cases except when Yule process and the calibration normal distribution are used together, in which case the estimate is at $33 \mathrm{Ma}( \pm 7 \mathrm{Ma})$.

\section{Historical biogeography reconstruction}

There was no statistical difference in the global likelihood between the non-time-stratified analyses NS0 and NS1 (Table 3). Excluding unlikely area connections (NS1), resulted in a Puerto Rico-northern Hispaniola (PR-nH) distribution on the crown node of Calisto, whereas NSO equally preferred $\mathrm{PR}$ along with both $\mathrm{nH}$ and $\mathrm{sH}$ (southern Hispaniola) (Table 4, Figure 3). Similarly, NS0 and NS1 were unable to discern between dispersal and vicariance for the origin of Cuban Calisto. The time-stratified analysis TS1 favoured vicariance over dispersal in all cases and TS2 inferred a PR-sH origin of Calisto and vicariance for the origin of Cuban diversity. However, TS2 analysis did not improve the global likelihood of the inference over TS1. Root optimizations significantly favoured a PR-sH distribution and vicariance as the cause of the Cuban clade split from its sister Hispaniolan lineages.

The estimation of the parameter $j$ (founder-event speciation) significantly improved the DEC models. The global likelihood of TS1 was improved using BioGeoBEARS because, in contrast to Lagrange $\mathrm{C}++$, we were able to constrain the area-connectivity through time slices. NS1-j preferred dispersal in critical nodes, i.e. the colonization of Jamaica, Cuba and the Bahamas, as well as a widespread origin of Calisto (PR-nH-sH) followed by vicariance. However, from all four models used in BioGeoBEARS, Akaike weights and likelihood-ratio test (LRT) suggested that TS1-j had a higher probability of being the best model, followed by TS1. Dispersal to Jamaica and the Bahamas are fully recovered in both TS1 and TS1-j from BioGeoBEARS, whereas vicariance is favoured as an explanation of the origin of Cuban Calisto only in TS1 analysis.

\section{Diversification processes within Calisto}

The $\Delta \mathrm{AIC}_{\mathrm{RC}}$ critical value for small phylogenies, as estimated in laser, is 4 [47]. The observed value for Calisto is significantly higher than this threshold $\left(\Delta \mathrm{AIC}_{\mathrm{RC}}=\right.$ $13)$, favouring a rate-variable diversification model. However, there was no statistical difference between the rate-variable models Yule-3-rates ( $\mathrm{Y} 3 \mathrm{r}$ ) and the logistic density-dependent $(\mathrm{DDL})\left(\triangle \mathrm{AIC} \mathrm{Y}_{3 \mathrm{r}}-\mathrm{DDL}=3.8\right)$. The diversification of the main Calisto tree excluding the Cuban lineage also fits the rate-variable process $\left(\triangle \mathrm{AIC}_{\mathrm{RC}}=11\right)$ better, but there was not strong preference among DDL, Yule-2, and -3-rates $\left(\triangle \mathrm{AIC} C_{\mathrm{DDL}}-\mathrm{Y3r}=\right.$ 2.0; $\left.\Delta \mathrm{AIC}_{\mathrm{DDL}}-\mathrm{Y} 2 \mathrm{r}=3.8\right)($ Table 5). 


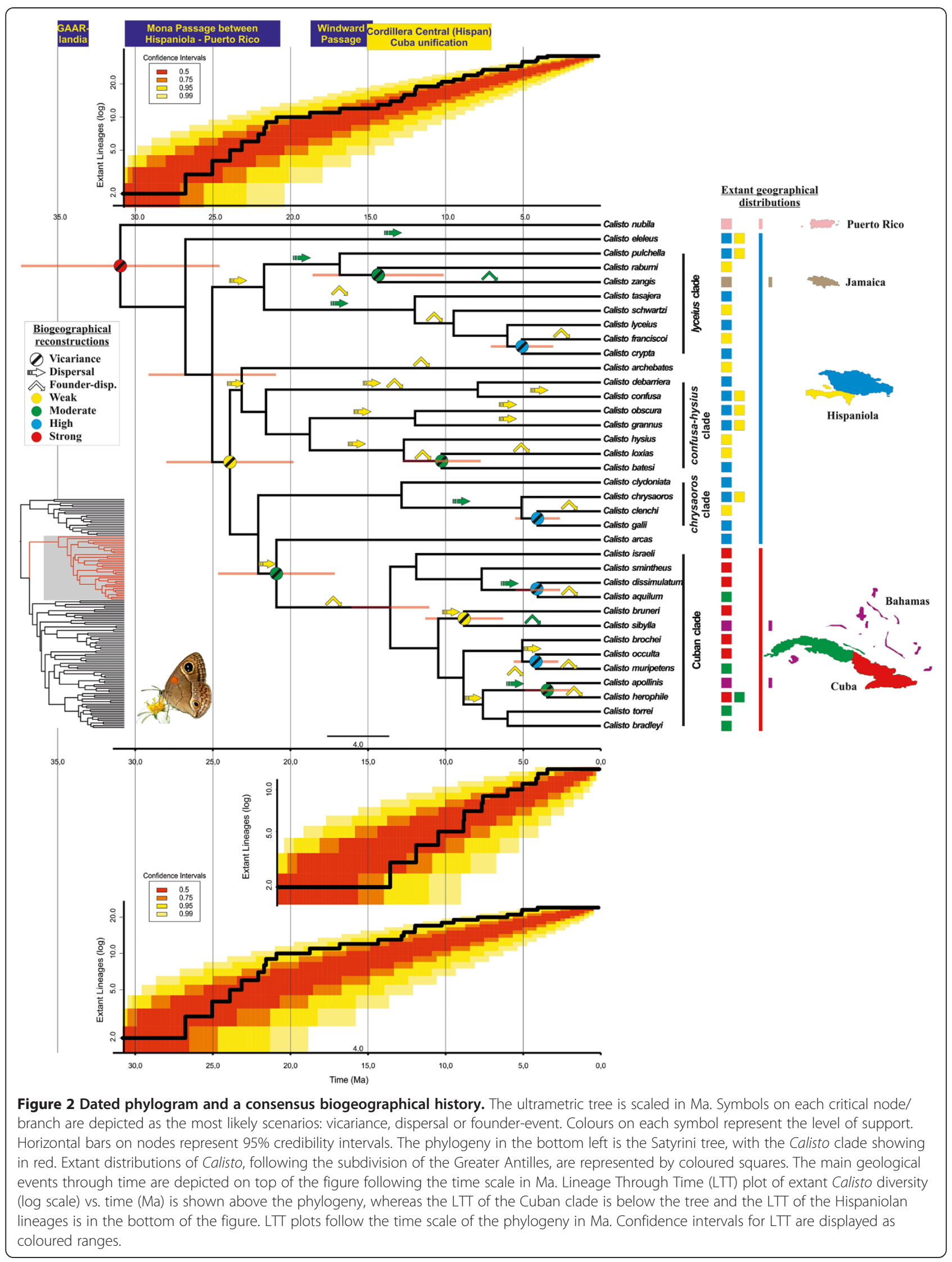


Table 2 Revised checklist of the genus Calisto (Lepidoptera: Nymphalidae: Satyrinae: Satyrini)

\begin{tabular}{|c|c|c|}
\hline Island & $\begin{array}{l}\text { Proposed species for } \\
\text { Calisto }\end{array}$ & $\begin{array}{l}\text { Classification within } \\
\text { Calisto }\end{array}$ \\
\hline Anegada & Calisto anegadensis & $\begin{array}{l}\text { Related to Calisto nubila. } \\
\text { Reference [26] }\end{array}$ \\
\hline Bahamas & Calisto apollinis & Cuban clade 2 \\
\hline Bahamas & Calisto sibylla & Cuban clade 2 \\
\hline Cuba & Calisto aquilum & Cuban clade 1 \\
\hline Cuba & Calisto bradleyi & Cuban clade 2 \\
\hline Cuba & Calisto brochei & Cuban clade 2 \\
\hline Cuba & Calisto bruneri & Cuban clade 2 \\
\hline Cuba & Calisto dissimulatum & Cuban clade 1 \\
\hline Cuba & Calisto herophile & Cuban clade 2 \\
\hline Cuba & Calisto israeli & Cuban clade 1 \\
\hline Cuba & Calisto muripetens & Cuban clade 2 \\
\hline Cuba & Calisto occulta & Cuban clade 2 \\
\hline Cuba & Calisto smintheus & Cuban clade 1 \\
\hline Cuba & Calisto torrei & Cuban clade 2 \\
\hline $\begin{array}{l}\text { Hispaniola (North } \\
\text { and South) }\end{array}$ & Calisto chrysaoros & chrysaoros clade \\
\hline $\begin{array}{l}\text { Hispaniola (North } \\
\text { and South) }\end{array}$ & Calisto confusa & confusa-hysius clade \\
\hline $\begin{array}{l}\text { Hispaniola (North } \\
\text { and South) }\end{array}$ & Calisto eleleus & Incertae sedis \\
\hline $\begin{array}{l}\text { Hispaniola (North } \\
\text { and South) }\end{array}$ & Calisto grannus & confusa-hysius clade \\
\hline $\begin{array}{l}\text { Hispaniola (North } \\
\text { and South) }\end{array}$ & Calisto obscura & confusa-hysius clade \\
\hline $\begin{array}{l}\text { Hispaniola (North } \\
\text { and South) }\end{array}$ & Calisto pulchella & lyceius clade \\
\hline Hispaniola (North) & Calisto ainigma & $\begin{array}{l}\text { Related to Calisto eleleus. } \\
\text { Reference [42] }\end{array}$ \\
\hline Hispaniola (North) & Calisto arcas & Incertae sedis \\
\hline Hispaniola (North) & Calisto batesi & confusa-hysius clade \\
\hline Hispaniola (North) & Calisto clydoniata & chrysaoros clade \\
\hline Hispaniola (North) & Calisto crypta & lyceius clade \\
\hline Hispaniola (North) & Calisto debarriera & confusa-hysius clade \\
\hline Hispaniola (North) & Calisto galii & chrysaoros clade \\
\hline Hispaniola (North) & Calisto Iyceius & lyceius clade \\
\hline Hispaniola (North) & Calisto neochma & $\begin{array}{l}\text { Related to Calisto } \\
\text { clydoniata. Reference [43] }\end{array}$ \\
\hline Hispaniola (North) & Calisto tasajera & lyceius clade \\
\hline Hispaniola (North) & Calisto wetherbeei & $\begin{array}{l}\text { Related to Calisto } \\
\text { archebates. Reference [44] }\end{array}$ \\
\hline Hispaniola (South) & Calisto archebates & Incertae sedis \\
\hline Hispaniola (South) & Calisto clenchi & chrysaoros clade \\
\hline Hispaniola (South) & Calisto franciscoi & lyceius clade \\
\hline Hispaniola (South) & Calisto hysius & confusa-hysius clade \\
\hline Hispaniola (South) & Calisto loxias & confusa-hysius clade \\
\hline
\end{tabular}

Table 2 Revised checklist of the genus Calisto (Lepidoptera: Nymphalidae: Satyrinae: Satyrini) (Continued)

\begin{tabular}{|c|c|c|}
\hline Hispaniola (South) & Calisto pauli & $\begin{array}{l}\text { Related to Calisto hysius } \\
\text { (C. herophile \& C. sibylla?). } \\
\text { Reference [45] }\end{array}$ \\
\hline Hispaniola (South) & Calisto raburni & lyceius clade \\
\hline Hispaniola (South) & Calisto schwartzi & lyceius clade \\
\hline Hispaniola (South) & Calisto thomasi & $\begin{array}{l}\text { Related to Calisto confusa. } \\
\text { Reference [45] }\end{array}$ \\
\hline Hispaniola (South) & Calisto tragius & $\begin{array}{l}\text { Related to Calisto eleleus. } \\
\text { Reference }[46]\end{array}$ \\
\hline Hispaniola (South) & Calisto woodsi & $\begin{array}{l}\text { Related to Calisto pauli. } \\
\text { Reference }[45]\end{array}$ \\
\hline Jamaica & Calisto zangis & lyceius clade \\
\hline Puerto Rico & Calisto nubila & Puerto Rican lineage \\
\hline
\end{tabular}

Each island and its fauna is shown according to the phylogenetic relationships presented in this study. Hispaniola is subdivided in northern and southern paleoislands. The eight species that were not included in this work are listed with their putative sister taxa.

From all rate-variable models in $D D D$, only those with a whole Calisto shift under diversity-dependent process are preferred with Akaike weights higher than 0.1. One single shift in the $K$ parameter ("clade-level carrying capacity") at $14 \mathrm{Ma}$ fits 2-3 times better than shifts in $K$ along with speciation or extinction rates. The decoupling of parameters for the Cuban taxa alone from the main Calisto tree was not enough to explain the radiation of the genus. Cuban and Hispaniolan taxa analyzed separately did not have constant diversification rates; rates changed possibly due to increased speciation, diversitydependence processes, or a combination of both (Akaike Weights were unable to discern among models). Including the number of missing taxa into the models when possible did not affect the recovered estimations (Table 6).

\section{Discussion}

\section{Colonization of the Greater Antilles by Calisto}

The variability in our dataset (39\% and $28 \%$ of all characters were variable and phylogenetically informative respectively; Table 1) is similar to previous inter-generic studies in Nymphalidae [32,48,49], but relatively higher than intra-generic studies [50,51]. The genus Calisto is most likely a "relict" satyrine group that might have colonized the Greater Antilles during the uplift of GAARlandia ( 35-33 Ma) [32]. Our dating estimates, indeed, confirm that it is an old and independent lineage, and its crown age $(31 \pm 5 \mathrm{Ma})$ provides evidence in support of the GAARlandia origin. Previous attempts to date the diversification of Calisto were done based only on a pairwise substitution rate for mitochondrial evolution [27]. This latter study deduced younger ages (4-8 Ma) but did not actually carry out a timing of the divergence analysis, rather they only calculated pairwise genetic distances 
Table 3 Estimated parameters and global likelihoods on each of the biogeographical analyses

\begin{tabular}{|c|c|c|c|c|c|c|c|c|c|}
\hline Non-stratified & Global in-likelihood & $d$ & $e$ & $j$ & Stratified & Global in-likelihood & $D$ & $e$ & $j$ \\
\hline Lagrange $\mathrm{C}++$ & & & & & Lagrange $\mathrm{C}++$ & & & & \\
\hline${ }^{*}$ NSO & -73.5273 & 0.2700 & 0.0102 & - & ${ }^{*} \mathrm{TS} 1$ & -88.2411 & 0.6363 & 0.0003 & - \\
\hline *NS1 & -73.8920 & 0.3872 & 0.0146 & - & TS2 & -93.1298 & 0.7224 & 0.0005 & - \\
\hline Root optimization & & & & & Root optimization & & & & \\
\hline${ }^{*}$ NS1_PR-sH & -72.1124 & 0.4854 & 0.0053 & - & *TS2_PR-sH & -94.3276 & 0.6718 & 0.0005 & - \\
\hline NS1_PR-nH & -74.5323 & 0.3517 & 0.0114 & - & TS2_PR-nH & -97.4394 & 0.6162 & 0.0025 & - \\
\hline NS1_PR-nH-eC & -76.5541 & 0.3825 & 0.0118 & - & TS2_PR-nH-eC & -97.6103 & 0.6174 & 0.0017 & - \\
\hline NS1_PR-sH-eC & -76.6322 & 0.3313 & 0.0086 & - & TS2_PR-nH-sH & -97.8598 & 0.5802 & 0.0019 & - \\
\hline NS1_PR-nH-sH & -77.1248 & 0.3048 & 0.0083 & - & TS2_PR-sH-eC & -98.4153 & 0.5613 & 0.0001 & - \\
\hline NS1_nH & -78.4231 & 0.3522 & 0.0141 & - & TS2_sH & -99.4647 & 0.7906 & 0.0050 & - \\
\hline NS1_PR & -80.0185 & 0.3219 & 0.0059 & - & TS2_nH & -101.7850 & 0.6684 & 0.0089 & - \\
\hline NS1_sH & -80.2485 & 0.2874 & 0.0082 & - & TpS2_PR & -103.8450 & 0.6690 & 0.0063 & - \\
\hline BioGeoBEARS DEC model & & & & & BioGeoBEARS DEC model & & & & \\
\hline *NS1-j & -78.7492 & 0.0020 & 0.0000 & 0.0709 & ${ }^{*} \mathrm{TS} 1-j$ & -63.8944 & 0.0581 & 0.0042 & 0.5821 \\
\hline NS1 & -97.9848 & 0.0054 & 0.0069 & - & TS1 & -76.7373 & 0.1211 & 0.0098 & - \\
\hline
\end{tabular}

The best models from each type of analyses are highlighted in bold text and marked with an asterisk (*). Parameter $d$ is the rate of "dispersal" or range expansion, $e$ is the rate of "extinction" or range contraction, and $j$ is the relative weight of jump dispersal. $j$ is cladogenetic, and $d$ and $e$ are anagenetic processes. Modelcomparison between the BioGeoBEARS models resulted in Akaike weights favouring TS1-j with a relative probability of 0.999 of it being the best model. Similarly, LRT between TS1 and TS1-j, the two best models, rejected TS1 as the null model with fewer parameters with $p$-value of $4.02 \mathrm{e}^{-07}$.

with Kimura 2-parameter without an adequate model testing.

It is not the first time that GAARlandia is invoked to explain butterfly geographic range expansion. It is the case for the nymphaline subtribe Phyciodina [52], the satyrine subtribe Pronophilina [32], and certain lineages within the papilionid tribe Troidini [53]. The idea of indirect overwater dispersal by "hitch hiking" on hurricanes or flotsams rafts seems unlikely. Adult butterflies respond to incoming bad weather by taking refuge [36] whereas a high mortality of eggs, larvae and pupae is observed when they are exposed to marine water [54]. Calisto, when compared to most other butterflies, are rather sedentary, and hence the direct and indirect dispersal capabilities of Calisto make a dispersalist model less likely.

According to Iturralde-Vinent's vicariance model [6], after GAARlandia, Hispaniola and Puerto Rico split around 20-30 Ma, whereas in our study, extant Calisto species in both islands have their most recent common ancestor at $27 \pm 5 \mathrm{Ma}$. Furthermore, the Cuban clade branched off from a Hispaniola lineage at $21 \pm 4 \mathrm{Ma}$, but did not apparently diversify into any extant Calisto until $14 \pm 3 \mathrm{Ma}$, while the last aerial connection between blocks of Hispaniola and Cuba existed until 14-17 Ma. Therefore, the evolution of Calisto is better explained by the main predictions of the Caribbean paleogeographical model of colonization rather than the stochastic dispersalist scenario.

The inclusion of Jamaica into the vicariance model is less supported by the paleogeographical reconstructions, although a remote connection between the Blue Mountains block with GAARlandia has not been discarded $[4,6]$. The sole extant Jamaican Calisto split from its Hispaniolan sister taxa at $14 \pm 4 \mathrm{Ma}$. At that time, large portions of Jamaica began to uplift and the entire island remained above water afterwards, and hence the colonization of Jamaica by rare long-distance dispersal events is the most likely explanation for the origin of the endemic sole species found there, Calisto zangis.

\section{Historical biogeography of Calisto}

Biogeographical reconstructions were significantly improved when we constrained dispersal probability and area-connectivity following the paleogeographic history of the Caribbean. Moreover, we found for the first time, statistical support for long-distance dispersal in the colonization of the Bahamas and Jamaica by estimating a founder-event parameter using a more general DEC model. Vicariance was recovered as the main explanation for the first diversification event of Calisto, although we did not find a fully supported dispersal/vicariance origin for the Cuban clade. Whereas NS1 and TS1 in BioGeoBEARS and TS2 did significantly recover vicariance, other analyses did not favour either dispersal nor vicariance. This could be due primarily to, first, the assumptions made by the models and, second, the different approaches to node reconstruction. In the first case, vicariance is favoured when incorporating area connectivity through time (TS) but dispersal is recovered by adding the parameter $j$ (founder-event or long-distance dispersal speciation). In the second case, Lagrange infers 
Table 4 Biogeographical reconstructions for the evolution of Calisto

\begin{tabular}{|c|c|c|c|c|c|c|c|c|}
\hline & & Crown Calisto & Stem Cuban Calisto & Stem Jamaican Calisto & Stem Bahamian C. sibylla & Stem Bahamian C. apollinis & $\begin{array}{l}\mathrm{N}^{\circ} \text { vicariant } \\
\text { events }\end{array}$ & $\begin{array}{l}\mathrm{N}^{\circ} \text { dispersal } \\
\text { events }\end{array}$ \\
\hline \multirow{8}{*}{$\begin{array}{c}\text { Lagrange } \\
\text { C++ }\end{array}$} & \multirow[t]{3}{*}{ NSO } & PR-sH: 0.24 (-74.94); & nH-eC: 0.44 (-74.34); & ${ }^{*}$ sH-Ja: 0.61 (-74.01); & eC-Ba: 0.55 (-74.12); & ${ }^{*}$ eC-wC-Ba: 0.83 (-73.71) & \multirow{3}{*}{8} & \multirow{3}{*}{5} \\
\hline & & PR-nH-sH: 0.16 (-75.36); & $\mathrm{nH}: 0.43$ (-74.36) & sH: 0.27 (-74.83) & eC: $0.42(-74.4)$ & & & \\
\hline & & PR-nH: $0.11(-75.7)$ & & & & & & \\
\hline & \multirow[t]{2}{*}{ NS1 } & *PR-nH: 0.48 (-74.62); & $\mathrm{nH}: 0.52$ (-74.55); & sH-Ja: 0.42 (-74.75); & eC-Ba: $0.5(-74.59) ;$ & ${ }^{*} e C-w C-B a: 0.81$ (-74.1) & \multirow{2}{*}{7} & \multirow{2}{*}{$12(1)$} \\
\hline & & PR-nH-sH: $0.16(-75.73)$ & nH-eC: 0.44 (-74.71) & $\mathrm{sH}: 0.32(-75.02)$ & eC: $0.48(-74.62)$ & & & \\
\hline & \multirow[t]{3}{*}{ TS2 } & PR-sH: 0.25 (-94.52); & ${ }^{*}$ nH-eC: 0.95 (-93.18) & ${ }^{*}$ sH-Ja: 0.97 (93.16) & ${ }^{*}$ eC-Ba: $0.96(-92.86)$ & ${ }^{*}$ eC-wC-Ba: 0.95 (-92.86) & \multirow{3}{*}{11} & \multirow{3}{*}{9} \\
\hline & & PR-nH-sH-eC: 0.22 (-94.6); & & & & & & \\
\hline & & PR-sH-eC: 0.22 (-94.6) & & & & & & \\
\hline \multirow{11}{*}{$\begin{array}{c}\text { BioGeoBEARS } \\
\text { DEC model }\end{array}$} & \multirow[t]{3}{*}{ NS1-j } & *PR-nH-sH: 0.92 & ${ }^{*} \mathrm{nH}: 0.68 ;$ & sH: 0.49; & eC: 0.49 ; & Ba: $0.4 ;$ & \multirow{3}{*}{1} & \multirow{3}{*}{$7(6)$} \\
\hline & & & eC: 0.29 & Ja: 0.45 & Ba: 0.48 & eC: 0.2 & & \\
\hline & & & & & & wC: 0.2 & & \\
\hline & \multirow[t]{3}{*}{ NS1 } & *PR-nH-sH: 0.73; & ${ }^{*} \mathrm{nH}-\mathrm{eC}: 0.52 ;$ & ${ }^{*}$ sH-Ja: 0.72 & *eC-Ba: 0.84 & ${ }^{*} e C-w C-B a: 0.66$ & \multirow{3}{*}{10} & \multirow{3}{*}{3} \\
\hline & & PR-sH: 0.22 & eC: 0.16 & & & eC-Ba: 0.16; & & \\
\hline & & & & & & wC-Ba: 0.16 & & \\
\hline & \multirow[t]{3}{*}{ TS1-j } & *PR-sH: 0.72; & $\mathrm{nH}: 0.57$ & ${ }^{*} \mathrm{sH}: 0.99$ & ${ }^{*} \mathrm{eC}: 0.81$ & eC: 0.38 & \multirow{3}{*}{1} & \multirow{3}{*}{$9(6)$} \\
\hline & & PR-nH-sH: 0.12 & eC: 0.37 & & wC: 0.18 & wC: 0.28 & & \\
\hline & & & & & & eC-wC: 0.27 & & \\
\hline & \multirow[t]{2}{*}{ TS1 } & *PR-sH: 0.84 & ${ }^{*} \mathrm{nH}-\mathrm{eC}: 0.66$; & ${ }^{*}$ sH: 0.99 & ${ }^{*} \mathrm{eC}: 0.65$ & eC-wC-Ba: 0.45; & \multirow{2}{*}{6} & \multirow{2}{*}{$9(5)$} \\
\hline & & & $\mathrm{nH}: 0.3$ & & WC: 0.21 & eC-Ba: 0.43 & & \\
\hline
\end{tabular}

We excluded from the comparison the TS1 from Lagrange because of the unrealistic scenarios that were recovered (see text). Critical nodes for testing the Caribbean paleogeographical (vicariance) model are shown with their correspondent reconstructed ancestral geographical range. Preferred node distributions are highlighted in bold text and preceded by an asterisk (*). The number of well-supported vicariance and dispersal

events were only counted when the relative probability of the best inference is two times larger than the following reconstructed distribution, in both immediate ancestral and daughter nodes. Dispersal events include the number of anagenetic range-switching and cladogenetic founder-events (the latter in parenthesis). 


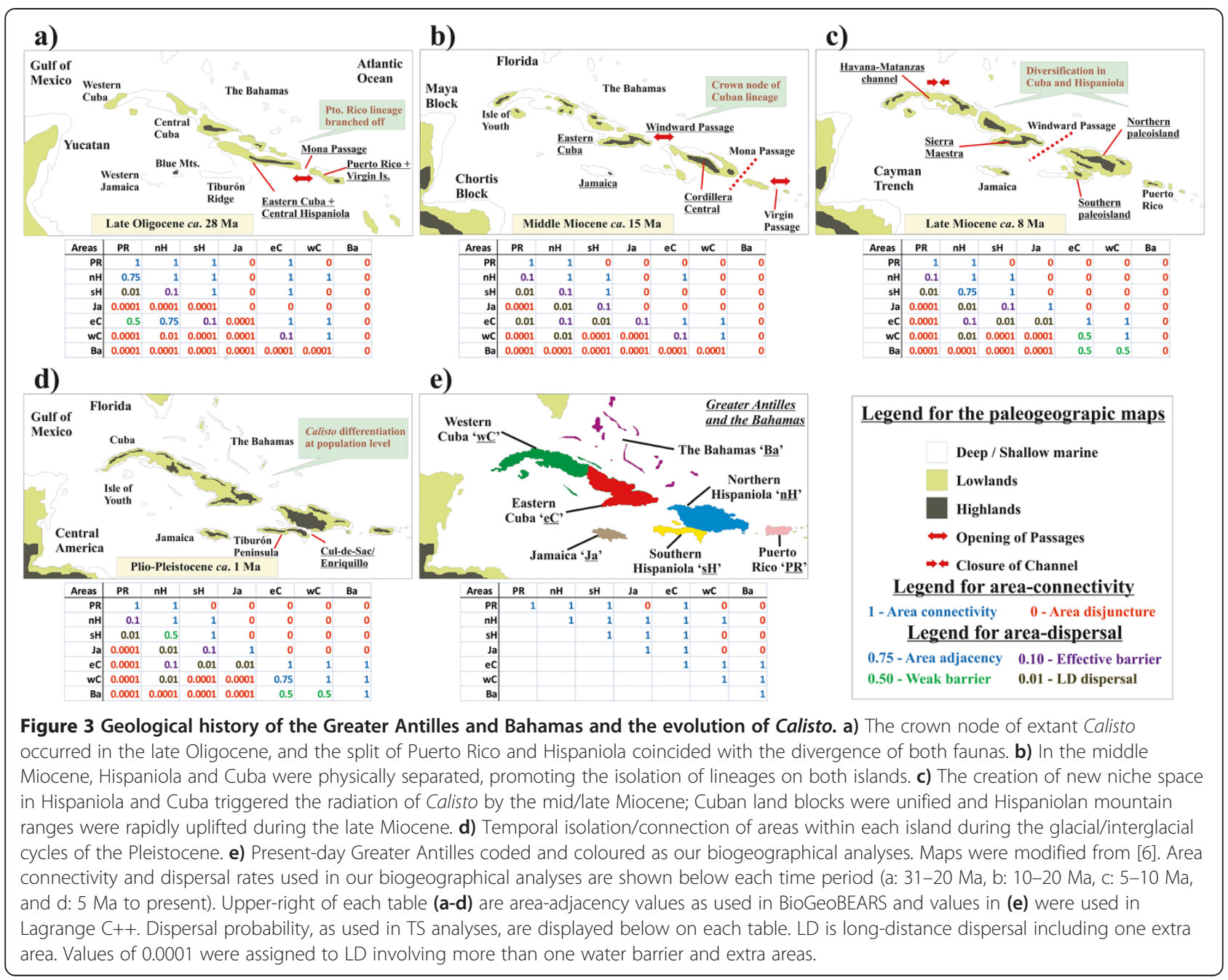

ancestral states by local optimization whereas BioGeoBEARS reports ancestral states under the most likely model. This difference is evidenced in NS1 (analysis replicated using both software programs) where vicariance is only reconstructed under the global most-likely inference by BioGeoBEARS.

We believe, given the paleogeographic scenario and our dating estimations which correlate with the former, that the most plausible explanation for the colonization of Cuba is vicariance. Furthermore, the whole of extant Cuban diversity is monophyletic and sister to a Hispaniola lineage, as predicted by the vicariant model. Dispersal into Cuba 10$25 \mathrm{Ma}$, on the other hand, was not "long-distance" because both land blocks were quite close apart, if not physically connected. Thus, if dispersal were actually the main process, we would expect several independent Cuban lineages of varied ages surviving to the present (see extinction rates in "Diversification of Calisto" section) (Figure 2).

Vicariance driving speciation within islands is significantly recovered for Hispaniolan fauna during two instances, at 10-13 Ma and 4-6 Ma. The first vicariant instance is independently evidenced in two lineages with simultaneous shifts in ancestral ranges, the lyceius and the confusa-hysius clades. The dating estimates are congruent with the major uplift of the Cordillera Central which might have provided new ecological opportunities and created isolated populations [39,40]. Presence of local adaptations are evidenced not only by the disjunctive distributions of several sister-species pairs found on the northern/southern Hispaniola paleoislands respectively (e.g. C. tasajera and C. schwartzi are allopatrically adapted to mesophilic and forested montane habitats in Cordillera Central (nH) and Sierra de Bahoruco (sH) $[46,55,56])$, but also by ecological niche restrictions. For instance, sister species-pairs within both major clades feed, as larvae, exclusively on distinct bunch grasses, and have morphologically adapted to specific altitudinal ranges. Species inhabiting lower altitude and warmer areas are smaller than their sister montane species $[27,46]$, suggesting an adaptation for thermoregulatory efficiency [57].

The second instance of vicariant process within Hispaniola occurred during the Pliocene as evidenced in the lyceius 
Table 5 Diversification dynamics of Calisto as reconstructed by the R package laser

\begin{tabular}{|c|c|c|c|c|c|c|c|c|c|c|c|}
\hline \multicolumn{12}{|c|}{ Diversification rates for Calisto } \\
\hline & LH & AIC & $r_{1}$ & $r_{2}$ & $r_{3}$ & a & $x$ & k & t_shift ${ }_{1}$ & t_shift ${ }_{2}$ & $\Delta$ AIC (yule-3-rates) \\
\hline $\mathrm{pb}$ & -32.301 & 66.602 & 0.07 & - & - & - & - & - & - & - & 13.32 \\
\hline$b d$ & -32.301 & 68.602 & 0.07 & - & - & 0 & - & - & - & - & 15.32 \\
\hline$d d x$ & -28.705 & 61.41 & 0.394 & - & - & - & 0.599 & - & - & - & 8.124 \\
\hline *ddl & -26.579 & 57.158 & 0.175 & - & - & - & - & 40.119 & - & - & 3.871 \\
\hline spvar & -28.84 & 63.681 & 0.229 & - & - & 0.004 & - & - & - & - & 10.39 \\
\hline exvar & -32.36 & 70.721 & 0.069 & - & - & 0.014 & - & - & - & - & 17.43 \\
\hline bothvar & -28.826 & 65.653 & 0.227 & - & - & 0.004 & - & - & - & - & 12.37 \\
\hline yule-2-rates & -26.056 & 58.112 & 0.094 & 0.014 & - & - & - & - & 4.079 & - & 4.826 \\
\hline *yule-3-rates & -21.643 & 53.286 & 0.21 & 0.083 & 0.007 & - & - & - & 20.903 & 4.058 & 0 \\
\hline \multicolumn{12}{|c|}{ Diversification rates for Calisto excluding Cuban clade } \\
\hline & LH & AIC & $r_{1}$ & $r_{2}$ & $r_{3}$ & a & $\mathrm{x}$ & k & t_shift 1 & t_shift ${ }_{2}$ & $\Delta \mathrm{AIC}$ (ddl) \\
\hline $\mathrm{pb}$ & -33.893 & 69.787 & 0.056 & - & - & - & - & - & - & - & 11.19 \\
\hline$b d$ & -33.893 & 71.787 & 0.056 & - & - & 0 & - & - & - & - & 13.19 \\
\hline$d d x$ & -29.428 & 62.855 & 0.55 & - & - & - & 0.889 & - & - & - & 4.258 \\
\hline *ddl & -27.299 & 58.597 & 0.186 & - & - & - & - & 24.646 & - & - & 0 \\
\hline spvar & -29.332 & 64.664 & 0.253 & - & - & 0.004 & - & - & - & - & 6.066 \\
\hline exvar & -33.951 & 73.902 & 0.055 & - & - & 0.018 & - & - & - & - & 15.3 \\
\hline bothvar & -29.323 & 66.646 & 0.251 & - & - & 0.004 & - & - & - & - & 8.048 \\
\hline *yule-2-rates & -28.178 & 62.355 & 0.073 & 0.016 & - & - & - & - & 5.11 & - & 3.758 \\
\hline *yule-3-rates & -25.313 & 60.626 & 0.21 & 0.055 & 0.008 & - & - & - & 20.903 & 5.079 & 2.029 \\
\hline
\end{tabular}

The best models for our data is either DDL or yule-3-rates, which are highlighted in bold text and with an asterisk (*). Both models, nonetheless, predict a decreasing in diversification rates through time. Excluding the Cuban clade resulted in DDL, yule-2 or yule-3-rates as the main processes for the diversification of Hispaniolan lineages. $\mathrm{LH}$ : the best recovered log-likelihood, $r_{i}$ : net diversification rate at time $i\left(\lambda_{\mathrm{i}}-\mu_{\mathrm{i}}\right)$, a: extinction fraction $\left(\mu_{\mathrm{i}} / \lambda_{\mathrm{i}}\right), X$ : parameter controlling the magnitude of rates (only in DDX), $k$ : parameter analogous to species "carrying capacity" (only in DDL), t_shift; diversification shift at time $i$. The diversification models are pure-birth (pb), birth-death (bd), density-dependent speciation rate model following exponential (ddx) or logistic variants (ddl), exponential decline of speciation with constant extinction (spvar), exponential increase of extinction with constant speciation (exvar), speciation and extinction changes through time (bothvar), and pure birth models with $n$ shifts in speciation (yule-n-rate).

and chrysaoros clades. Although an uplift of the Cordillera Central might have played a role in separating populations, the most likely explanation for the northern/southern paleoislands distributions might be related to the inundation of the Cul-de-Sac/Enriquillo depression, which acted as an effective barrier. Ecological niche shifts might be another plausible explanation for the lyceus clade members having differentiated during the Pliocene. As larvae, they feed on the bunchgrass Uniola virgata, which provides a unique niche and would have required significant adaptations [56].

The crown node ancestral distribution of Cuban and Bahamian Calisto is recovered as "eastern Cuba $(\mathrm{eC})$ ". Its sister taxa are Hispaniolan lineages that occur in the northwestern Cordillera Central (Massif du Nord in Haiti) [22,46], which is the closest region to eastern Cuba. Dispersal to central and western Cuba from "eC" appears to be the likeliest biogeographic scenario [28], although vicariance as the main process is only detected in NS1 from BioGeoBEARS. Dispersal dates are in line with the closure of the Havana-Matanzas Channel at
8-5 Ma, as well as with the accretion of Bahamian shallows and keys in the Pliocene/Pleistocene [6]. The two Bahamian lineages have distinct ancestral areas, while $C$. sibylla has an older origin and its source area is "eC", $C$. apollinis dispersed more recently from "western Cuba (wC)" (Figure 3).

\section{Calisto diversification on the Greater Antilles and the \\ Bahamas}

The species richness of Calisto across islands is largely unequal. Such a pattern has been previously reported as the consequence of island size and age, ecological limits and habitat diversity $[8,38,58]$. Munroe $[59,60]$ pointed out that extant Calisto diversity is distributed unequally among islands more likely due to speciation rather than to differential immigration, and that extinction was extremely low, especially in Hispaniola. The calculation of diversification rates and ancestral states in this study suggested that the extant geographical distribution of Calisto reflects the rapid diversification within Hispaniola 


\begin{tabular}{|c|c|c|c|c|c|c|c|c|c|c|c|c|c|c|c|c|c|c|c|}
\hline & & \multirow[b]{2}{*}{$\lambda_{0}$} & \multirow[b]{2}{*}{$\mu_{0}$} & \multirow[b]{2}{*}{$\mathrm{K}_{0}$} & \multirow[b]{2}{*}{$\lambda_{1}$} & \multirow[b]{2}{*}{$\mu_{1}$} & \multirow[b]{2}{*}{$\mathrm{K}_{1}$} & \multirow[b]{2}{*}{ t_shift } & \multirow[b]{2}{*}{$\log -\mathrm{LH}$} & \multirow[b]{2}{*}{$\begin{array}{l}\text { Akaike } \\
\text { weight }\end{array}$} & \multicolumn{9}{|c|}{ Analyses account 8 missing species } \\
\hline & & & & & & & & & & & $\lambda_{0}$ & $\mu_{0}$ & $\mathrm{~K}_{0}$ & $\lambda_{1}$ & $\mu_{1}$ & $\mathrm{~K}_{1}$ & t_shift & $\log -\mathrm{LH}$ & $\begin{array}{l}\text { Akaike } \\
\text { weight }\end{array}$ \\
\hline & Calisto diversification & & & & & & & & & & & & & & & & & & \\
\hline CRO & constant $\lambda$ and $\mu$ (birth-death) & 0.07 & 0 & - & - & - & - & - & -124.437 & 0.00 & 0.08 & 0 & - & - & - & - & - & -123.853 & 0.00 \\
\hline CR1 & $\begin{array}{l}\lambda \text { declining as div-dep. № } \mu \\
\text { (DDL) }\end{array}$ & 0.175 & - & 40.119 & - & - & - & - & -118.715 & 0.03 & - & - & - & - & - & - & - & - & - \\
\hline CR2 & $\begin{array}{l}\text { div-dep with } \mu(\mathrm{DDL}+\mathrm{E}) \\
\text { depend in } \lambda\end{array}$ & 0.163 & 0 & 43.055 & - & - & - & - & -118.926 & 0.01 & 0.163 & 0 & 54.745 & - & - & - & - & -118.774 & 0.02 \\
\hline SRO & Yule-2-rate & 0.122 & - & 36.641 & 0.3 & - & $\mathrm{K}_{0}$ & 13.567 & -116.243 & 0.12 & 0.122 & - & 45.321 & 0.298 & - & K1 & 13.567 & -116.487 & 0.16 \\
\hline *SR1 & shift in $K$ & 0.306 & 0 & 13.132 & $\lambda_{0}$ & $\mu_{0}$ & 36.62 & 13.567 & -113.877 & 0.48 & 0.295 & 0 & 14.456 & $\lambda_{0}$ & $\mu_{0}$ & 45.466 & 13.567 & -114.384 & 0.47 \\
\hline SR2 & shift in $\mathrm{K}$ and $\mu$ & 0.306 & 0 & 13.13 & $\lambda_{0}$ & 0 & 36.617 & 13.567 & -113.878 & 0.18 & 0.3 & 0.006 & 14.342 & $\lambda_{0}$ & 0 & 45.355 & 13.567 & -114.369 & 0.18 \\
\hline SR3 & shift in $\mathrm{K}$ and $\lambda$ & 0.322 & 0 & 13.025 & 0.298 & $\mu_{0}$ & 36.713 & 13.567 & -113.863 & 0.18 & 0.289 & 0 & 14.507 & 0.298 & $\mu_{0}$ & 45.414 & 13.567 & -114.382 & 0.17 \\
\hline KI1 & shift in $\mathrm{K}$ in subclade & 0.133 & 0 & 27.172 & $\lambda_{0}$ & $\mu_{0}$ & Inf. & 13.567 & -118.634 & 0.00 & 0.139 & 0 & 37.103 & $\lambda_{0}$ & $\mu_{0}$ & Inf. & 13.567 & -121.355 & 0.00 \\
\hline KI2 & shift in $\mathrm{K}$ and $\mu$ in subclade & 0.133 & 0 & 27.159 & $\lambda_{0}$ & 0 & Inf. & 13.567 & -118.651 & 0.00 & 0.139 & 0 & 36.965 & $\lambda_{0}$ & 0 & Inf. & 13.567 & -121.371 & 0.00 \\
\hline KI3 & shift in $\mathrm{K}$ and $\lambda$ in subclade & 0.164 & 0 & 25.591 & 0.115 & $\mu_{0}$ & Inf. & 13.567 & -118.319 & 0.00 & 0.17 & 0 & 34.419 & 0.114 & $\mu_{0}$ & $\operatorname{lnf}$ & 13.567 & -120.853 & 0.00 \\
\hline \multirow[t]{2}{*}{ KI4 } & shift in $K, \lambda$ and $\mu$ in subclade & 0.162 & 0 & 25.779 & 0.111 & 0 & Inf. & 13.567 & -118.302 & 0.00 & 0.17 & 0 & 34.434 & 0.114 & 0 & Inf. & 13.567 & -120.852 & 0.00 \\
\hline & $\begin{array}{l}\text { Hispaniolan lineages } \\
\text { diversification }\end{array}$ & & & & & & & & & & & & & & & & & & \\
\hline CRO & constant $\lambda$ and $\mu$ (birth-death) & 0.056 & 0 & - & - & - & - & - & -85.5 & 0.00 & 0.066 & 0 & - & - & - & - & - & -84.936 & 0.00 \\
\hline CR1 & $\begin{array}{l}\lambda \text { declining as div-dep. No } \mu \\
\text { (DDL) }\end{array}$ & 0.186 & - & 24.646 & - & - & - & - & -78.905 & 0.19 & - & - & - & - & - & - & - & - & - \\
\hline CR2 & $\begin{array}{l}\text { div-dep with } \mu(\mathrm{DDL}+\mathrm{E}) \\
\text { depend in } \lambda\end{array}$ & 0.165 & 0 & 26.665 & - & - & - & - & -80.231 & 0.02 & 0.166 & 0 & 36.387 & - & - & - & - & -79.968 & 0.04 \\
\hline SRO & Yule-2-rate & 0.141 & - & 24 & 0.335 & - & $\mathrm{K}_{0}$ & 12.843 & -77.021 & 0.17 & 0.141 & - & 32 & 0.347 & - & K1 & 12.843 & -77.219 & 0.20 \\
\hline *SR1 & shift in $K$ & 0.33 & 0.001 & 11.991 & $\lambda_{0}$ & $\mu_{0}$ & 23.918 & 14.352 & -75.372 & 0.32 & 0.339 & 0.001 & 15.518 & $\lambda_{0}$ & $\mu_{0}$ & 31.942 & 12.843 & -75.477 & 0.42 \\
\hline SR2 & shift in $\mathrm{K}$ and $\mu$ & 0.318 & 0.001 & 11.964 & $\lambda_{0}$ & 0 & 24 & 14.352 & -75.219 & 0.14 & 0.327 & 0 & 15.593 & $\lambda_{0}$ & 0 & 32.023 & 12.844 & -75.427 & 0.16 \\
\hline \multirow[t]{2}{*}{ SR3 } & shift in $\mathrm{K}$ and $\lambda$ & 0.333 & 0 & 12.98 & 0.245 & $\mu_{0}$ & 24.135 & 12.843 & -75.09 & 0.16 & 0.295 & 0.001 & 15.743 & 0.355 & $\mu_{0}$ & 31.948 & 12.843 & -75.372 & 0.17 \\
\hline & Cuban lineage diversification & & & & & & & & & & & & & & & & & & \\
\hline CRO & constant $\lambda$ and $\mu$ (birth-death) & 0.09 & 0 & - & - & - & - & - & -40.903 & 0.01 & - & - & - & - & - & - & - & - & - \\
\hline CR1 & $\begin{array}{l}\lambda \text { declining as div-dep. No } \mu \\
\text { (DDL) }\end{array}$ & 0.27 & - & 14.568 & - & - & - & - & -38.31 & 0.14 & - & - & - & - & - & - & - & - & - \\
\hline CR2 & $\begin{array}{l}\text { div-dep with } \mu(\mathrm{DDL}+\mathrm{E}) \\
\text { depend in } \lambda\end{array}$ & 0.219 & 0 & 17.498 & - & - & - & - & -39.235 & 0.02 & - & - & - & - & - & - & - & - & - \\
\hline
\end{tabular}


Table 6 Diversification dynamics of Calisto as reconstructed by the $\mathrm{R}$ package DDD (Continued)

\begin{tabular}{|c|c|c|c|c|c|c|c|c|c|c|c|c|c|c|c|c|c|c|c|}
\hline *SRO & Yule-2-rate & 0.099 & - & 14 & 0.493 & - & $\mathrm{K}_{0}$ & 10.475 & -35.409 & 0.35 & - & - & - & - & - & - & - & - & - \\
\hline SR1 & shift in $\mathrm{K}$ & 0.502 & 0.012 & 2.323 & $\lambda_{0}$ & $\mu_{0}$ & 13.644 & 11.894 & -35.377 & 0.13 & - & - & - & - & - & - & - & - & - \\
\hline *SR2 & shift in $K$ and $\mu$ & 0.426 & 0.024 & 1.864 & $\lambda_{0}$ & 0 & 13.982 & 13.567 & -33.981 & 0.20 & - & - & - & - & - & - & - & - & - \\
\hline SR3 & shift in $K$ and $\lambda$ & 0.162 & 0.009 & 1.884 & 0.466 & $\mu_{0}$ & 13.718 & 13.573 & -34.287 & 0.15 & - & - & - & - & - & - & - & - & - \\
\hline
\end{tabular}

The best models for each type of analyses, which include extinction and diversity-dependent processes, are highlighted in bold text and with an asterisk (*). $\lambda$ is speciation rate, $\mu$ is extinction rate, $\mathrm{K}$ is species "carrying capacity" or a parameter analogous to it only in DDL. The estimated parameters to the right were calculated accounting missing taxa (8 species). The DDL model is not able to incorporate missing taxa whereas the Cuban clade in this study included all described species. A shift in $\mathrm{K}$ is recovered as the best explanation for the diversification patterns of Calisto and the Hispaniolan lineages. Yule-2-rate or a shift in $\mathrm{K}$ and $\mu$ are the best models to explain the diversification of the Cuban clade alone. 
and Cuba during two instances, at 25 and $14 \mathrm{Ma}$, while inter-island flow was negligible for the entire genus.

Calisto is the most species-rich butterfly genus in the West Indies because it was able to expand its ecological niche (e.g. feeding on distinct bunchgrasses, tolerance to montane temperate and tropical conditions), which raised up the "ecological limits" on Calisto diversification. One sole change in the $K$ parameter ("carrying-capacity for species diversity") is enough to explain the evolution of the whole genus. The recovered date of this shift at $14 \mathrm{Ma}$ is congruent with an increase in ecological opportunity in Hispaniola and Cuba and a time at which new environments were being created as a result of geological processes (e.g. uplift of Cordilleras, unification of Cuban land blocks) $[39,40]$. The decoupling of clade "carrying capacity" and/or diversification rates of the Cuban lineage as the only explanation for the genus species richness is not supported. Nonetheless, the arrival of Calisto to an unoccupied island of Cuba did certainly provide for new heretofore empty niches to be colonized. The most likely scenario for such a decoupling was at $14 \mathrm{Ma}$, as recovered in DR1 analysis. However, because such a date is confounded with the availability of new niches in Hispaniola, a model including one single shift in $K$ for the whole genus was preferred.

Adaptive radiation and the origin of island endemism of West Indies insects remain statistically untested. Under a phylogenetic framework, indirect evidence of adaptive radiation could be inferred based on diversification rate shifts: i.e. a rapid increase followed by a gradual reduction of diversification rate under a diversity-dependent process [61]. Calisto butterflies might have undergone two increases in diversification before they rapidly reached a "carrying-capacity" limit. The first one occurred during the uplift of Cordillera Central at $25 \mathrm{Ma}$ (SR1 analysis), triggering a growth in Calisto diversification rate until all available niches were gradually occupied, at which time, probably, the speciation rate declined linearly with diversity $(K=12)$. It is unlikely that the extinction rate rose, as it was near zero in all of our estimations. The second major radiation took place at $14 \mathrm{Ma}$ (discussed above), but it is more plausible that the diversification rate increased due to a shift in $K$ rather than by a sole increase in speciation rate. Furthermore, the "Inf." values of $K$ recovered for the Cuban clade in DR analyses might be an indication that the diversification rate has not yet reached its "ecological limit". The Cuban clade, when analyzed independently, better fits a 2-yule-rate, with 5 times larger speciation rate at $10 \mathrm{Ma}$ than when the lineage branched off at 21 Ma.

An intriguing question is why the observed diversification dynamics of Calisto on Cuba and Hispaniola were not replicated on Jamaica and Puerto Rico, the third and fourth largest islands of the West Indies, respectively.
Whereas Calisto are usually locally adapted to particular habitats within Cuba and Hispaniola, the single species on each of the other two islands are widespread. While some diverse Hispaniolan lineages feed as larvae on bunch grasses, the Puerto Rican C. nubila is adapted to widespread-wide-blade grass feeding [56]. According to Turner, similar, relatively adaptable oviposition behaviour is exhibited by C. zangis of Jamaica [62]. Perhaps in this indiscriminate behaviour lies the explanation for the fact that these two species were able to colonize their entire respective islands instead of forming separate disjunctive populations as did their Hispaniolan congeners. Such wide distribution and relatively good dispersal abilities of these relatively larger Calisto species (Sourakov, pers. obs.) may have increased gene flow and hence prevented divergence. Further research on the natural history, dietary preferences and behaviour of Calisto is necessary to corroborate our speculations.

\section{Conclusions}

The phylogenetic and biogeographical evidence presented in this study agrees with the Caribbean paleogeographical model of colonization (Figures 2 and 3). Vicariant models explaining the diversification of Calisto have already been proposed based on their extant geographical distribution $[31,33,36,60]$, although some authors had favoured the alternative dispersalist explanation $[27,63]$. Here we observed that the evolution of Calisto passed through both vicariant processes and long-distance dispersals. However, the most important means for diversity origination in this largest genus of West Indies butterflies, was intra-island rapid radiation through key innovations (e.g. unusual larval hostplant, adaptation to montane, temperate and tropical conditions) and the availability of ecological niches triggered by environmental changes (e.g. accretion of mountain ranges, different island configuration and areaconnectivity through time). Nonetheless, more rigorous tests and associations between ecological niche spectrum, phenotypic variability and selection within these butterflies are needed to give the adequate weight to abiotic factors (geographic and climatic) and niche specializations in the observed burst followed by a slowdown in diversification rates.

\section{Methods}

\section{Taxon sampling}

We included 36 out of the 44 described Calisto species (Additional file 2). Species sampling took place across the entire geographical distribution of the genus in the Greater Antilles, except for the Anegada Island where only one species occurs. Our analyses also included DNA sequences previously reported from taxa across the tribe Satyrini and Calisto [27-29,32] (Additional file 2). Species identifications were based on morphology and the DNA 
barcode region was used for further corroboration [64]. Voucher photographs are available at the Nymphalidae Systematics Group (NSG) Voucher Database (nymphalidae. utu.fi) and in BOLD (boldsystems.org).

\section{Dataset acquisition}

Genomic DNA was isolated from two butterfly legs using the QIAGEN's DNeasy kit. We used sequences of six standard molecular markers for nymphalid butterflies, one mitochondrial - COI (1487 bp) - and five nuclear genes - CAD (850 bp), EF-1 $\alpha$ (1240 bp), GAPDH (691 bp), RpS5 (617) and wingless (400 bp). Primer pair sequences and laboratory protocols are described in [65]. DNA Sanger sequencing was carried out by the company Macrogen and each gene sequence was edited and manually aligned using the program BioEdit v7.0.5 [66]. Datasets were generated in different input formats using the web application VoSeq v1.7.0 [67].

\section{Phylogenetic analyses}

We used single-gene and combined datasets. We partitioned our single-gene datasets by codon position and our combined dataset by gene sequences in all analyses. In addition we used character groupings of similar relative evolutionary rates as an alternative strategy for Bayesian Inference (BI) [68], after determining that the gene trees were not in conflict with each other. We used the software TIGER [69] to subdivide our combined dataset into 12 "bins" each containing a number of characters with similar relative rates: $\operatorname{bin} 1=2739$, bin 2 to $\operatorname{bin} 5=0, \operatorname{bin} 6=12, \operatorname{bin} 7=7, \operatorname{bin} 8=21, \operatorname{bin} 9=87, \operatorname{bin} 10=$ 525 , bin $11=1269$ and bin $12=637$. We combined the "bins" that contained fewer than 500 sites (bin2 to bin9) with the invariable bin1, resulting in four character groupings which were used for our alternative partitioning approach (Table 1).

We performed 1000 Maximum Likelihood (ML) pseudo-replicates analyses using RaXML v7.3.1 [70] on the Bioportal server [71], selecting the thorough bootstrap algorithm and the mix option for the evolutionary model. The BI analyses were carried out using MrBayes v3.2.1 [72] on the Bioportal server. We performed 10 million generations with sampling every 1000 generation and four chains, one cold and three heated, for two independent runs. The parameters and models of evolution were unlinked across character partitions. We selected the mixed evolutionary model option in all BI analyses whereas in the alternative partitioning strategy, we selected the corresponding model for each "bin" as calculated in jModelTest 0.1.1 [41] based on Bayesian Information Criterion (BIC). The convergence of the two runs on each BI was ascertained by visual inspection of the log-likelihoods stationary distribution, discarding the first $25 \%$ sampled trees, as well as by checking that the final average standard deviation of split frequencies was below 0.05 and that the potential scale reduction factor (PSRF) for each parameter was close to 1 .

\section{Time of diversification estimates}

Because there is no fossil record reported for the genus, we reconstructed a broader phylogeny including most of the representatives of the Satyrini subtribes that are closely related to Calisto [32] (Additional file 2) and constrained it with secondary calibration points from a fossil-calibrated Nymphalidae phylogeny [73]. We selected only one terminal per Calisto species to maximize the gene coverage in the resulting dataset. We also made an analysis excluding the genus Euptychia because long branch attraction affecting the position of Calisto has been reported [32]. The selected calibration points were chosen from well-supported monophyletic groups: the root of the tree to $49.1 \pm 5 \mathrm{Ma}$, the crown age of the tribe Satyrina to $24.7 \pm 4 \mathrm{Ma}$ and the crown age of Euptychiina excluding Euptychia, Paramacera and Cyllopsis to $35.1 \pm 4 \mathrm{Ma}$.

The dating analyses were run in BEAST v1.7.4 [74] and executed on the Bioportal server. We partitioned our dataset by gene sequence and set the corresponding substitution model as calculated in jModelTest (Table 1) and the uncorrelated log-normal relaxed clock model for each partition. We applied either the Birth-Death or the Calibrated Yule speciation processes as the tree prior in separate analyses to investigate the impact of this parameter on the final age estimates. In addition, the calibration points were modelled as either normal distributions (soft bounds) or uniform ranges (hard bounds). Finally, we set the mean rate of the molecular clock (ucld prior) with a uniform distribution between 0.0 and 10.0 and left other priors as default.

Each analysis was run four independent times for 50 million generations each and sampling trees and parameters every 5000th generation. We discarded the first 2500 sampled trees from each run as burnin. We verified in Tracer v1.5 the convergence and good mixing of MCMC as well as the Effective Sample Size of each estimated parameter to be higher than 200. Output .log and .tre files were combined in LogCombiner v1.7.4 after resampling a third of the post-burnin trees from each run. Trees were summarized in TreeAnnotator v1.7.4 into a single maximum clade credibility tree with node information calculated as mean heights.

\section{Historical biogeography reconstruction}

We used our dated chronogram for Calisto as the input tree, excluding outgroups and C. pulchella because its distribution has been altered by sugar cane introduction, on which it is currently a pest [33]. The following subdivision of areas was set: "PR" - Puerto Rico; "nH" - the 
northern Hispaniola paleoisland, including Cordillera Central/Massif du Nord, Sierra de Neiba/Chaîne des Matheux, and eastern Hispaniola; "sH" - the southern Hispaniola paleoisland, including Sierra de Bahoruco/ Chaîne de la Selle and Massif de la Hotte in Tiburón Peninsula; "Ja" - Jamaica; "eC" - the eastern Cuba, including Nipe - Sagua - Baraoca and Sierra Maestra mountain ranges; "wC" - the central and western Cuba, including Guamuhaya and Guaniguanico mountain ranges; "Ba" the Bahamas. Distributional ranges of Calisto were taken from several sources [22,27-29,33,46].

We used the Dispersal-Extinction-Cladogenesis (DEC) model as implemented in Lagrange $\mathrm{C}++[75,76]$. DEC is a realistic and flexible model for biogeographical reconstructions that estimates the probabilities (likelihoods) of ancestral geographical distributions, and it allows the parameterization of dispersal through time according to the geological history of a region. We conducted analyses using a non-time-stratified approach (NS) and different dispersal rates across time slices (stratified, TS). The nontime-stratified analysis NSO was conducted under default settings. The maximum distributional range was constrained to three areas and we excluded distributions with unlikely area-connectivity (e.g. Puerto Rico and Western Cuba) in NS1 analysis. TS1 used four time slices, subdividing the phylogeny at $5 \mathrm{Ma}, 10 \mathrm{Ma}$ and $20 \mathrm{Ma}$. Dispersal rate matrices were constructed according to the paleogeographical configuration on each time slice. Probabilities to disperse were set to 0.75 when two areas were adjacent, to 0.5 when two areas were weakly separated by a geographical barrier (e.g. the Cul-de-Sac/ Enriquillo depression), to 0.1 when two areas were separated by water of a distance less than $200 \mathrm{~km}$ (e.g. northern Hispaniola and eastern Cuba), to 0.01 for longdistance dispersal, including one extra area and/or $>200 \mathrm{~km}$ water-crossing (e.g. Puerto Rico to southern Hispaniola), and to 0.0001 for other kinds of long-distance dispersal.

We found a particular node in TS1 analysis to be unlikely (the Cuban-Bahamian subclade including C. sibylla and $C$. apollinis). This group had a crown age of $10 \pm$ $2 \mathrm{Ma}$ and an ancestral range eC-Ba after TS1. Paleogeographically, this is improbable because the Bahamas were submerged at least until the Pliocene $(\sim 5 \mathrm{Ma})$. We thus constrained such node to "eC" in TS2 because Lagrange, as it is currently implemented, does not allow the exclusion of unlikely area-connectivity through time slices.

Moreover, several sets of area distribution were independently constrained at the root of the Calisto tree to maximize the global likelihood of NS1 and TS2 and to compare the statistical support of likely ancestral ranges. We also used the $\mathrm{R}$ package BioGeoBEARS [77,78] which implements the DEC model similar to Lagrange $\mathrm{C}++$ but with the possibility of increasing the number of free parameters. We allowed the founder-event speciation parameter $j$ to be estimated in NS1- $j$ and TS1- $j$ to evaluate the importance of long-distance dispersal across islands. Another advantage of BioGeoBEARS is that distinct area-connection through time is allowed, hence we created an areaconnectivity matrix for each time slice in TS1 and TS1-j (Figure 3).

\section{Diversification of Calisto}

We used the packages laser [79], ape [80] and DDD $[61,81]$ in $R[82]$ to investigate the mode of diversification of extant Calisto taxa. Lineage Through Time (LTT) plots with confidence intervals representing a pure-birth null hypothesis model were made using ape. We compared different models of cladogenesis allowing temporal shifts in diversification rates using the Akaike Information Criterion differentials $\left(\triangle \mathrm{AIC}_{\mathrm{RC}}=\mathrm{AIC}_{\mathrm{RC}}\right.$ (best rate-constant model) - $\mathrm{AIC}_{\mathrm{RV}}$ (best rate-variable model)) as implemented in laser. We also computed the $\triangle \mathrm{AIC}_{\mathrm{RC}}$ separately for the Calisto phylogeny, excluding the Cuban species.

We used the R package $D D D$ to fit the best phylogenetic diversification model that would explain the evolutionary history of Calisto. The analyses included three main models: a constant-rate evolution (CR), a shift in net diversification rate at some point in time (SR) and a decoupling of rates between the Cuban clade and the remaining taxa (DR). CR models incorporated either constant birth-death process (CR0), a decrease in speciation rate following a density-dependent process without extinction (CR1) or a decrease in speciation rate following a diversity-dependent process, including the estimation of extinction rate (CR2). SR models were set up to: one shift in speciation rate (yule-2-rate model) (SR0), one shift in species carrying capacity $K$ (SR1), one shift in $K$ and extinction rate (SR2), or one shift in $K$ and speciation rate (SR3). DR models described one single shift in $K$ for the Cuban clade (DR1), one shift in $K$ and extinction rate for the Cuban clade (DR2), one shift in $K$ and speciation rate for the Cuban group (DR3), and one shift in $K$, speciation and extinction rates for Cuban taxa (DR4). Moreover, we conducted CR and SR analyses for the main Calisto tree, excluding the Cuban clade, and for the Cuban clade independently. Comparisons between different phylogenetic diversification models were done using Akaike weights.

\section{Availability of supporting data}

The data sets supporting the results of this article are available in the TreeBASE repository, in http://purl.org/phylo/ treebase/phylows/study/TB2:S16186?format=html [83].

\section{Additional files}

Additional file 1: Additional phylogenetic trees of Calisto. In order of appearance in the pdf file: gene trees using COI (page 1), CAD (page 2), EF1a (page 3), GAPDH (page 4), RpS5 (page 5) and wingless (page 6) single 
gene datasets in MrBayes. Each node displays posterior probabilities values Calibrated Calisto trees as estimated using BEAST including the genus Euptychia and using priors on calibration points and speciation process respectively: Normal and Birth-Death (BD) (page 7), Normal and Yule (page 8), Uniform and BD (page 9), Uniform and Yule (page 10). Calibrated Calisto trees excluding the genus Euptychia and using: Normal and BD (page 11), Normal and Yule (page 12), Uniform and BD (page 13), Uniform and Yule (page 14). On the calibrated trees, posterior probabilities are displayed on each node, 95\% confidence interval for the dating estimates are shown as bars on each node, two red stars on every tree show the calibration points that were used in the present study and the $y$-axis represents time in million years. Subtribes names are represented on the left of each clade.

\section{Additional file 2: List of specimens and voucher information used in} the present study. A. xls file displaying each sequenced gene are presented with their corresponding GenBank accession number, unless the sequence is not available in the database where a " $X$ " is shown. The hyphen "-" indicates unsuccessful DNA sequencing for that particular gene.

\section{Abbreviations}

Ma: Million years ago; AIC: Akaike information criterion; DEC: Dispersal-

Extinction-Cladogenesis model; BI: Bayesian inference; ML: Maximum likelihood.

\section{Competing interests}

The authors declare that they have no competing interests.

\section{Authors' contributions}

NW and PMM conceived the initial research plan, AS, CP, JYM, RNA and NW collected and provided the specimens for this study; PMM, RNA and CP did the majority of the laboratory work and PMM, most of the data analyses. PMM wrote the first draft of the manuscript and the rest of the authors contributed actively to the final version. All authors read and approved the final manuscript.

\section{Acknowledgements}

We thank A.V.Z. Brower, F.L. Condamine, Alexandra Sourakov and an anonymous reviewer for their constructive comments on an early version of this study. We are also grateful to N.J. Matzke, R.S. Etienne and J. Smrčková for their advice on the biogeographical and diversification rate analyses. We thank Kelvin Guerrero for help with acquiring permits and collecting samples in the Dominican Republic. The National Geographic Society funded some of the fieldwork through Committee for Research and Exploration grant \#5717-96. The Kone Foundation is thanked for funds used in laboratory work. P.M.M. acknowledges the funds from Oskar Öflunds Foundation, Turun yliopistosäätiö and GAJU grant 156/2013/P. Thomas Turner is acknowledged for contributing a key specimen used in the DNA analysis.

\section{Author details}

'Laboratory of Genetics, Department of Biology, University of Turku, FI-20014 Turku, Finland. ${ }^{2}$ School of Biological Sciences, University of South Bohemia and Institute of Entomology, Biology Centre AS CR, CZ-37005 Ceske Budejovice, Czech Republic. ${ }^{3}$ División de Colecciones Zoológicas y Sistemática, Instituto de Ecología y Sistemática, Carretera de Varona km 3.5, Capdevila, Boyeros, Ciudad de La Habana, Cuba. ${ }^{4}$ McGuire Center for Lepidoptera and Biodiversity, Florida Museum of Natural History, University of Florida, Gainesville, FL 32611, USA.

Received: 8 May 2014 Accepted: 2 September 2014

Published online: 16 September 2014

\section{References}

1. Darlington PJ: The origin of the fauna of the Greater Antilles, with discussion of dispersal of animals over water and through the air. Q Rev Biol 1938, 13:274-300.

2. Hedges SB, Hass CA, Maxson LR: Caribbean biogeography: molecular evidence for dispersal in West Indian terrestrial vertebrates. Proc Natl Acad Sci U S A 1992, 89:1909-1913.

3. Hedges SB: Historical biogeography of West Indian vertebrates. Annu Rev Ecol Syst 1996, 27:163-196.

4. Dávalos LM: Phylogeny and biogeography of Caribbean mammals. Biol J Linn Soc 2004, 81:373-394.
5. Rosen DE: A vicariance model of Caribbean biogeography. Syst Zool 1975, 24:431-464.

6. Iturralde-Vinent MA: Meso-Cenozoic Caribbean paleogeography: implications for the historical biogeography of the region. Int Geol Rev 2006, 48:791-827.

7. Ricklefs RE, Cox GW: Taxon cycles in the West Indian avifauna. Am Nat 1972, 106:195-219.

8. Losos JB, Schluter D: Analysis of an evolutionary species-area relationship. Nature 2000, 408:847-850.

9. Alonso R, Crawford AJ, Bermingham E: Molecular phylogeny of an endemic radiation of Cuban toads (Bufonidae: Peltophryne) based on mitochondrial and nuclear genes. J Biogeogr 2012, 39:434-451.

10. Ali JR: Colonizing the Caribbean: is the GAARlandia land-bridge hypothesis gaining a foothold? J Biogeogr 2012, 39:431-433.

11. Van Gestel J-P, Mann P, Grindlay NR, Dolan JF: Three-phase tectonic evolution of the northern margin of Puerto Rico as inferred from an integration of seismic reflection, well, and outcrop data. Mar Geol 1999, 161:257-286.

12. MacPhee RDE, Iturralde-Vinent MA, Gaffney ES: Domo de Zaza, an early Miocene vertebrate locality in south-central Cuba, with notes on the tectonic evolution of Puerto Rico and the Mona Passage. Am Museum Novit 2003, 3394:1-42.

13. Pindell JL, Barrett SF: Geological evolution of the Caribbean Region: a plate-tectonic perspective. In Geol North Am Vol H, Caribb Reg. Edited by Dengo G, Case JE. Boulder, CO: Geological Society of America; 1990:405-432.

14. Hedges SB: Biogeography of the West Indies: an overview. In Biogeogr West Indies Patterns Perspect. Edited by Woods CA, Sergile FE. Boca Raton: CRC Press; 2001:15-33.

15. Graham A: Models and Cenozoic paleoenvironments of the Caribbean region. Syst Bot 2003, 28:378-386.

16. Lewis JF, Draper G: Geology and tectonic evolution of the Northern Caribbean Margin. In Geol North Am Vol H, Caribb Reg. Edited by Dengo G, Case JE. Boulder, CO: Geological Society of America; 1990:77-140.

17. Heubeck C, Mann P: Structural geology and cenozoic tectonic history of the Southeastern termination of the Cordillera Central, Dominican Republic. In Geol Tecton Dev North Am - Caribb plate Bound Hisp. Edited by Mann P, Draper G, Lewis JF. Geological Society of America Special Paper 262; 1991:315-336.

18. Maurrasse FJ-MR, Pierre-Louis F, Rigaud J-G: Cenozoic facies distribution in the Southern Peninsula of Haiti and the Barahona Peninsula, Dominican Republic. Trans 9th Caribb Geol Conf 1980, 1:161-174.

19. Robinson E: Jamaica. In Caribb Geol An Introd. Edited by Donovan SK, Jackson TA. Kingston, Jamaica: University of the West Indies Publishers Association; 1994:111-127.

20. Pindell J: Evolution of the Gulf of Mexico and the Caribbean. In Caribb Geol An Introd. Edited by Donovan SK, Jackson TA. Kingston, Jamaica: The University of West Indies Publishers Association; 1994:13-40.

21. Hearty PJ, Neumann AC: Rapid sea level and climate change at the close of the Last Interglaciation (MIS 5e): evidence from the Bahama Islands. Quat Sci Rev 2001, 20:1881-1895.

22. Michener CD: A review of the genus Calisto (Lepidoptera, Satyrinae). Am Museum Novit 1943, 1236:1-6.

23. Lamas G: Atlas of Neotropical Lepidoptera: Checklist: Part 4A. HesperioideaPapilionoidea, Volume 5A. Gainesville, Florida: Association for Tropical Lepidoptera; 2004. xxxvi + 439 .

24. Scott JA: Biogeography of Antillean butterflies. Biotropica 1972, 4:32-45.

25. Fontenla JL: Biogeography of Antillean butterflies (Lepidoptera: Rhopalocera): patterns of association among areas of endemism. Trans Am Entomol Soc 2003, 129:399-410.

26. Smith DS, Miller LD, KcKenzie F: The butterflies of Anegada, British Virgin Islands, with descriptions of a new Calisto (Satyridae) and a new Copaeodes (Hesperiidae) endemic to the island. Bull Allyn Mus 1991, 133:1-25.

27. Sourakov A, Zakharov EV: "Darwin's butterflies"? DNA barcoding and the radiation of the endemic Caribbean butterfly genus Calisto (Lepidoptera, Nymphalidae, Satyrinae). Comp Cytogenet 2011, 5:191-210.

28. Núñez Aguila R, Oliva Plasencia E, Matos Maravi PF, Wahlberg N: Cuban Calisto (Lepidoptera, Nymphalidae, Satyrinae), a review based on morphological and DNA data. Zookeys 2012, 165:57-105.

29. Núnez Aguila R, Matos-Maraví PF, Wahlberg N: New Calisto species from Cuba, with insights on the relationships of Cuban and Bahamian taxa (Lepidoptera, Nymphalidae, Satyrinae). Zootaxa 2013, 3669:503-521. 
30. Miller LD: The higher classification, phylogeny and zoogeography of the Satyridae (Lepidoptera). Mem Am Entomol Soc 1968, 24:1-174.

31. Viloria AL: Historical biogeography and the origins of the satyrine butterflies of the tropical andes (Lepidoptera: Rhopalocera). In Una Perspect Latinoam la Biogeogr. Edited by Morrone JJ, Llorente J. México: Universidad Nacional Autónoma de México; 2003:247-261.

32. Peña C, Nylin S, Wahlberg N: The radiation of Satyrini butterflies (Nymphalidae: Satyrinae): a challenge for phylogenetic methods. Zool J Linn Soc 2011, 161:64-87.

33. Smith DS, Miller LD, Miller JY: The Butterflies of the West Indies and South Florida. Oxford: Oxford University Press; 1994:264.

34. Riley ND: A Field Guide to the Butterflies of the West Indies. London: Collins; 1975:224.

35. Brown FM: The origins of the West Indian butterfly fauna. In Zoogeography Caribb. Edited by Gill FB. Pennsylvania: Academy of Natural Sciences of Philadelphia, Special Publication No. 13; 1978:5-30.

36. Miller JY, Miller LD: The biogeography of the West Indian butterflies (Lepidoptera): an application of a vicariance/dispersalist model. In Biogeogr West Indies Patterns Perspect. 2nd edition. Edited by Woods CA, Sergile FE. Florida: CRC Press LLC; 2001:127-155.

37. Miller LD, Miller JY: The Biogeography of the West Indian Butterflies (Lepidoptera: Papilionidea, Hesperioidea): a Vicariance model. In Biogeogr West Indies Past, Present Futur. Edited by Woods CA. Gainesville, Florida: Sandhill Crane Press; 1989:229-262.

38. Rabosky DL, Glor RE: Equilibrium speciation dynamics in a model adaptive radiation of island lizards. Proc Natl Acad Sci U S A 2010, 107:22178-22183.

39. Sly ND, Townsend AK, Rimmer CC, Townsend JM, Latta SC, Lovette IJ: Ancient islands and modern invasions: disparate phylogeographic histories among Hispaniola's endemic birds. Mol Ecol 2011, 20:5012-5024.

40. Oneal E, Otte D, Knowles LL: Testing for biogeographic mechanisms promoting divergence in Caribbean crickets (genus Amphiacusta). J Biogeogr 2010, 37:530-540.

41. Posada D: jModelTest: phylogenetic model averaging. Mol Biol Evol 2008, 25:1253-1256

42. Johnson K, Quinter EL, Matusik D: A new species of Calisto from Hispaniola with a review of the female genitalia of Hispaniolan congeners (Satyridae). J Res Lepid 1987, 25:73-82.

43. Schwartz A: A new species of Calisto from the Cordillera Central, Republica Dominicana. Milwaukee Public Museum, Contrib to Biol Geol 1991, 81:1-3.

44. Schwartz A, Gonzalez FL: A new species of Calisto (Satyridae) from Hispaniola. Bull Allyn Mus 1988, 117:1-5

45. Johnson K, Hedges SB: Three new species of Calisto from Southwestern Haiti (Lepidoptera: Nymphalidae: Satyrinae). Trop Lepid 1998, 9:45-53.

46. Schwartz A: The Butterflies of Hispaniola. Gainesville: University Presses of Florida; 1989:583.

47. Rabosky DL: Likelihood methods for detecting temporal shifts in diversification rates. Evolution (N Y) 2006, 60:1152-1164.

48. Peña C, Nylin S, Freitas AVL, Wahlberg N: Biogeographic history of the butterfly subtribe Euptychiina (Lepidoptera, Nymphalidae, Satyrinae). Zool Scr 2010, 39:243-258.

49. Matos-Maraví PF, Peña C, Willmott KR, Freitas AVL, Wahlberg N: Systematics and evolutionary history of butterflies in the "Taygetis clade" (Nymphalidae: Satyrinae: Euptychiina): towards a better understanding of Neotropical biogeography. Mol Phylogenet Evol 2013, 66:54-68.

50. Elias M, Joron M, Willmott K, Silva-Brandão KL, Kaiser V, Arias CF, Gomez Piñerez LM, Uribe S, Brower AVZ, Freitas AVL, Jiggins CD: Out of the Andes: patterns of diversification in clearwing butterflies. Mol Ecol 2009, 18:1716-1729

51. Kodandaramaiah $U$, Wahlberg N: Phylogeny and biogeography of Coenonympha butterflies (Nymphalidae: Satyrinae) - patterns of colonization in the Holarctic. Syst Entomol 2009, 34:315-323.

52. Wahlberg N, Freitas AVL: Colonization of and radiation in South America by butterflies in the subtribe Phyciodina (Lepidoptera: Nymphalidae). Mol Phylogenet Evol 2007, 44:1257-1272.

53. Condamine FL, Silva-Brandão KL, Kergoat GJ, Sperling FAH: Biogeographic and diversification patterns of Neotropical Troidini butterflies (Papilionidae) support a museum model of diversity dynamics for Amazonia. BMC Evol Biol 2012, 12:82.

54. Fox RM: Affinities and distribution of Antillean Ithomiidae. J Res Lepid 1963, 2:173-184.
55. Hedges SB, Johnson K: Calisto tasajera in the Hispaniolan Cordillera Central (Lepidoptera: Nymphalidae: Satyrinae). Trop Lepid 1994, 5:93-94.

56. Sourakov A: Notes on the genus Calisto, with descriptions of the immature stages (Part II) (Lepidoptera: Nymphalidae: Satyrinae). Trop Lepid 2000, 10:73-79.

57. Shelly TE, Ludwig D: Thermoregulatory behavior of the butterfly Calisto nubila (Satyridae) in a Puerto Rican forest. Oikos 1985, 44:229-233.

58. MacArthur RH, Wilson EO: The Theory of Island Biogeography. Princeton, NJ: Princeton University Press; 1967:203.

59. Munroe EG: The Geographical Distribution of Butterflies in the West Indies. Ithaca, New York, USA: Cornell University; 1948:1-1100.

60. Munroe EG: The systematics of Calisto (Lepidoptera, Satyrinae), with remarks on the evolutionary and zoogeographic significance of the genus. J New York Entomol Soc 1950, 58:211-240.

61. Etienne RS, Haegeman B: A conceptual and statistical framework for adaptive radiations with a key role for diversity dependence. Am Nat 2012, 180:E75-E89.

62. Brown FM, Heineman B: Jamaica and its Butterflies. London: E. W. Classey; 1972:478+xV.

63. Wetherbee DK: Eighth Contribution on the Larvae And/or Larval Host Plants of Hispaniolan Butterflies: The Butterfly/larva Flora with a Theory of Calisto (Satyridae) Origin and Endemicity. Shelburne, Massachsetts: Selfpublished; 1992:1-173.

64. Hebert PDN, Cywinska A, Ball SL, DeWaard JR: Biological identifications through DNA barcodes. Proc R Soc B Biol Sci 2003, 270:313-321.

65. Wahlberg N, Wheat CW: Genomic outposts serve the phylogenomic pioneers: designing novel nuclear markers for genomic DNA extractions of Lepidoptera. Syst Biol 2008, 57:231-242.

66. Hall TA: BioEdit: a user-friendly biological sequence alignment editor and analysis program for Windows 95/98/NT. Nucleic Acids Symp Ser 1999, 41:95-98.

67. Peña C, Malm T: VoSeq: a voucher and DNA sequence web application. PLOS ONE 2012, 7:e39071

68. Rota J, Wahlberg N: Exploration of data partitioning in an eight-gene dataset: phylogeny of metalmark moths (Lepidoptera, Choreutidae). Zool Scr 2012, 41:536-546.

69. Cummins CA, Mclnerney JO: A method for inferring the rate of evolution of homologous characters that can potentially improve phylogenetic inference, resolve deep divergence and correct systematic biases. Syst Biol 2011, 60:833-844.

70. Stamatakis A: RAxML-VI-HPC: maximum likelihood-based phylogenetic analyses with thousands of taxa and mixed models. Bioinformatics 2006, 22:2688-2690.

71. Kumar S, Skjæveland Å, Orr RJS, Enger P, Ruden T, Mevik B-H, Burki F, Botnen A, Shalchian-Tabrizi K: AIR: a batch-oriented web program package for construction of supermatrices ready for phylogenomic analyses. BMC Bioinformatics 2009, 10:357.

72. Ronquist F, Teslenko M, Van der Mark P, Ayres DL, Darling A, Höhna S, Larget B, Liu L, Suchard MA, Huelsenbeck JP: MrBayes 3.2: efficient Bayesian phylogenetic inference and model choice across a large model space. Syst Biol 2012, 61:539-542.

73. Wahlberg N, Leneveu J, Kodandaramaiah U, Peña C, Nylin S, Freitas AVL, Brower AVZ: Nymphalid butterflies diversify following near demise at the Cretaceous/Tertiary boundary. Proc R Soc B Biol Sci 2009, 276:4295-4302.

74. Drummond AJ, Suchard MA, Xie D, Rambaut A: Bayesian phylogenetics with BEAUti and the BEAST 1.7. Mol Biol Evol 2012, 29:1969-1973.

75. Ree RH, Smith SA: Maximum likelihood inference of geographic range evolution by dispersal, local extinction, and cladogenesis. Syst Biol 2008, 57:4-14.

76. Smith SA: Taking into account phylogenetic and divergence-time uncertainty in a parametric biogeographical analysis of the Northern Hemisphere plant clade Caprifolieae. J Biogeogr 2009, 36:2324-2337.

77. Matzke NJ: BioGeoBEARS: BioGeography with Bayesian (and Likelihood) Evolutionary Analysis in R Scripts. 2013. http://cran.r-project.org/web/ packages/BioGeoBEARS/index.html.

78. Matzke NJ: Probabilistic historical biogeography: new models for founder-event speciation, imperfect detection, and fossils allow improved accuracy and model-testing. Front Biogeogr 2013, 5:242-248.

79. Rabosky DL: LASER: a maximum likelihood toolkit for detecting temporal shifts in diversification rates from molecular phylogenies. Bioinformatics 2006, 2:247-250 
80. Paradis E, Claude J, Strimmer K: APE: analyses of phylogenetics and evolution in R language. Bioinformatics 2004, 20:289-290.

81. Etienne RS, Haegeman B: DDD: Diversity-Dependent Diversification. 2013 http://cran.r-project.org/web/packages/DDD/index.html.

82. R Core Team: R: A language and environment for statistical computing. 2013. www.r-project.org.

83. Matos-Maraví P, Núñez Águila R, Peña C, Miller JY, Sourakov A, Wahlberg N: DNA sequence data from the butterfly genus Calisto (Nymphalidae: Satyrinae: Satyrini). TreeBASE database. 2014. http://purl.org/phylo/treebase/phylows/ study/TB2:S16186?format=html.

doi:10.1186/s12862-014-0199-7

Cite this article as: Matos-Maravi et al: Causes of endemic radiation in the Caribbean: evidence from the historical biogeography and diversification of the butterfly genus Calisto (Nymphalidae: Satyrinae: Satyrini). BMC Evolutionary Biology 2014 14:199.

\section{Submit your next manuscript to BioMed Central and take full advantage of:}

- Convenient online submission

- Thorough peer review

- No space constraints or color figure charges

- Immediate publication on acceptance

- Inclusion in PubMed, CAS, Scopus and Google Scholar

- Research which is freely available for redistribution 